\title{
Temporal Variability of the Wind Wave Parameters in the Baltic Sea in 1979-2018 Based on the Numerical Modeling Results
}

\author{
A. N. Sokolov ${ }^{1,2, *, B . ~ V . ~ C h u b a r e n k o ~}{ }^{1}$ \\ ${ }^{1}$ Shirshov Institute of Oceanology, Russian Academy of Sciences, Moscow, Russia \\ ${ }^{2}$ Immanuel Kant Baltic Federal University, Kaliningrad, Russia \\ * tengritag@gmail.com
}

Purpose. The aim of the paper is to identify possible trends in the wave climate dynamics in the Baltic Sea, and to analyze statistical significance of the coefficients of these trends based on the results of their numerical modeling for 1979-2018.

Methods and Results. The simulations for 1979-2018 (40 years) were carried out on an irregular grid using the MIKE $21 S W$ spectral wave model. The wind forcing was preset according to the ERAInterim reanalysis data. The model was calibrated and validated against the data of wave buoys located in the northern and southern parts of the Baltic Sea. Based on the calibrated model, the wind wave parameters were calculated for the whole Baltic Sea area from 1979 to 2018 with the interval 1 hour. These parameters became the initial data for estimating temporal variability of the wind wave heights in the Baltic Sea for 40 years. The simulation results obtained on the irregular grid were interpolated to the regular one. It permitted to construct the maps of distribution of the maximum and average (for the 40-year period) significant wave heights in the Baltic Sea. The time trends for the average annual significant wave height values were revealed, and statistical significance of the coefficients of these trends was estimated.

Conclusions. The average annual values of the significant wave heights over almost the whole Baltic Sea area for 1979-2018 (40 years) tend to decrease with the rate not exceeding 2-3 cm $(\sim 2-3 \%)$ per 10 years. The highest rate reduction is observed in the southeastern part of the Baltic Sea, the lowest - in the Gulf of Bothnia and the Gulf of Finland. Interannual variability of the average annual significant wave heights and the changes along the trend during the entire 40-years period are of the same order.

Keywords: Baltic Sea, wind waves, temporal variability, numerical simulation.

Acknowledgments: the work was carried out within the framework of theme No. 0149-2019-0013 of the State Assignment of IO RAS and with the RFBR support, grant No. 18-05-80035 (methodological part).

For citation: Sokolov, A.N. and Chubarenko, B.V., 2020. Temporal Variability of the Wind Wave Parameters in the Baltic Sea in 1979-2018 Based on the Numerical Modeling Results. Physical Oceanography, [e-journal] 27(4), pp. 352-363. doi:10.22449/1573-160X-2020-4-352-363

DOI: $10.22449 / 1573-160 X-2020-4-352-363$

(C) A. N. Sokolov, B. V. Chubarenko, 2020

(C) Physical Oceanography, 2020

\section{Introduction}

The most complete information in Russian about the wind and wave regime in the Baltic Sea is provided by the Russian Maritime Register of Shipping ${ }^{1}$. The present article describes the calculation methodology and also provides extreme and operational statistical characteristics of wind and waves for different sea areas. The temporal variability of the wind wave height is not considered in it.

\footnotetext{
${ }^{1}$ Russian Maritime Register of Shipping, 2006. [Reference Data on the Wind and Wave Regime of the Baltic, North, Black, Azov and Mediterranean Seas]. Saint Petersburg: Russian Maritime Register of Shipping, 452 p. Available at: https://meganorm.ru/Data2/1/4293747/4293747775.pdf [Accessed: 06 July 2020] (in Russian).
} 
The work [1] is based on the analysis of field data, measurements of the wave parameters by anchored wave buoys installed in different parts of the Baltic Sea. According to this data, the authors conclude that there is a positive trend of the average annual significant wave height (the average value of the height for $1 / 3$ of the highest waves in the wave spectrum) in the northeastern part of the Central Baltic. It should be noted that the period considered in this work (16 years - from 1979 to 1995) is relatively short for climatic trends assessment. In addition, since measurement buoys are installed only in a few areas of the Baltic Sea, their data interpolation does not give a reliable result for the entire sea.

The majority of works of recent years [2-5], the wave climate (change trends, spatial and temporal variability, etc.) analyzed in throughout the Baltic Sea, the method of mathematical modeling is used. As the atmospheric forcing, atmospheric reanalysis data (hereinafter referred to as reanalysis), i.e., data on the wind characteristics over the Baltic Sea at the nodes of a regular (by geographic coordinates) grid, reconstructed over the historical period using various atmospheric models, is applied. The approach using numerical modeling permits to use calibrated and validated (according to wave buoy data) mathematical models (for example, [2]) to get an idea of the wave climate of the entire sea, about the average and extreme characteristics of the wave climate [4].

Model analysis of the temporal variability of the parameters of wind waves in the Baltic Sea was carried out in the works of T. Soomere and A. Räämet $[5,6]$, in which specific numerical values of the coefficients of temporal trends are given. The calculations were carried out using the WAM model, geostrophic wind was used as the atmospheric forcing. The work [5] indicates a notable decrease in the average annual values of a significant wave height after 1995 .

The work [3] shows the research of the wind waves in the Baltic for 19482010 (63 years) according to the results of calculations in the SWAN model under the surface wind influence, obtained from the NCEP/NCAR reanalysis data. The analysis showed a positive time trend in the number of storm situations leading to the appearance of waves with a significant height of more than $2 \mathrm{~m}$, as well as an increase in the average annual significant wave height for these storm situations (from 2.9 to $3.1 \mathrm{~m}$ according to the trend). Against the background of the revealed positive trend, significant interannual variability of the average annual significant wave height (from 2.4 to $3.3 \mathrm{~m}$ ) was noted, including a decrease in the values of this magnitude for the entire sea after 1990. In addition, a discrepancy between the trends of the decadal variability of these values in different regions of the Baltic Sea is noted in this article.

The present study is aimed to analyze possible trends in the dynamics of the wave climate in the Baltic Sea and their statistical significance based on the numerical modeling results (taking into account ice cover) for 1979-2018 (40 years). The ice cover can remain from 1 to 3 months on $80-100 \%$ of the Gulf of Bothnia, $70 \%$ of the Gulf of Finland and even $40 \%$ of the northern part of the Central Baltic [7, p. 320-329]. In contrast to [3], the ERA-Interim reanalysis data is used as the atmospheric forcing in the present work. To take into account the difference in the variability of wave characteristics in various areas of the sea, an approach based on the analysis of characteristic points is applied [8]. 


\section{Numerical model and its implementation}

The MIKE 21 SW [9] spectral wave model of the Danish Hydraulic Institute (DHI) was used to obtain a data array of wind wave parameters. The calculation is based on solving the balance equation for the wave action density

$$
\frac{\partial N}{\partial t}+\frac{\partial}{\partial x} c_{x} N+\frac{\partial}{\partial y} c_{y} N+\frac{\partial}{\partial \omega} c_{\omega} N+\frac{\partial}{\partial \theta} c_{\theta} N=\frac{S}{\omega},
$$

where $\theta$ is the direction of wave propagation; $\omega$ is the circular frequency; $c_{x}, c_{y}, c_{\omega}$ and $c_{\theta}$ are propagation velocities of wave group.

According to equation (1), variation of the density of the wave action in the control volume (depending on time, advection in geographic space, relative frequency shift due to changes in depth and currents, refraction and diffraction) is balanced by the source function $S$, which, according to equation (2), is a superposition of the following functions

$$
S=S_{\mathrm{in}}+S_{\mathrm{nl}}+S_{\mathrm{ds}}+S_{\mathrm{bot}}+S_{\mathrm{surf}}
$$

where $S_{\text {in }}$ - wind action leading to appearance of waves; $S_{\mathrm{nl}}$ is the wave energy redistribution as a result of nonlinear wave interactions; $S_{\mathrm{ds}}, S_{\mathrm{bot}}, S_{\mathrm{surf}}$ is the wave energy dissipation due to whitecapping, bottom friction and depth-induced breaking, respectively.

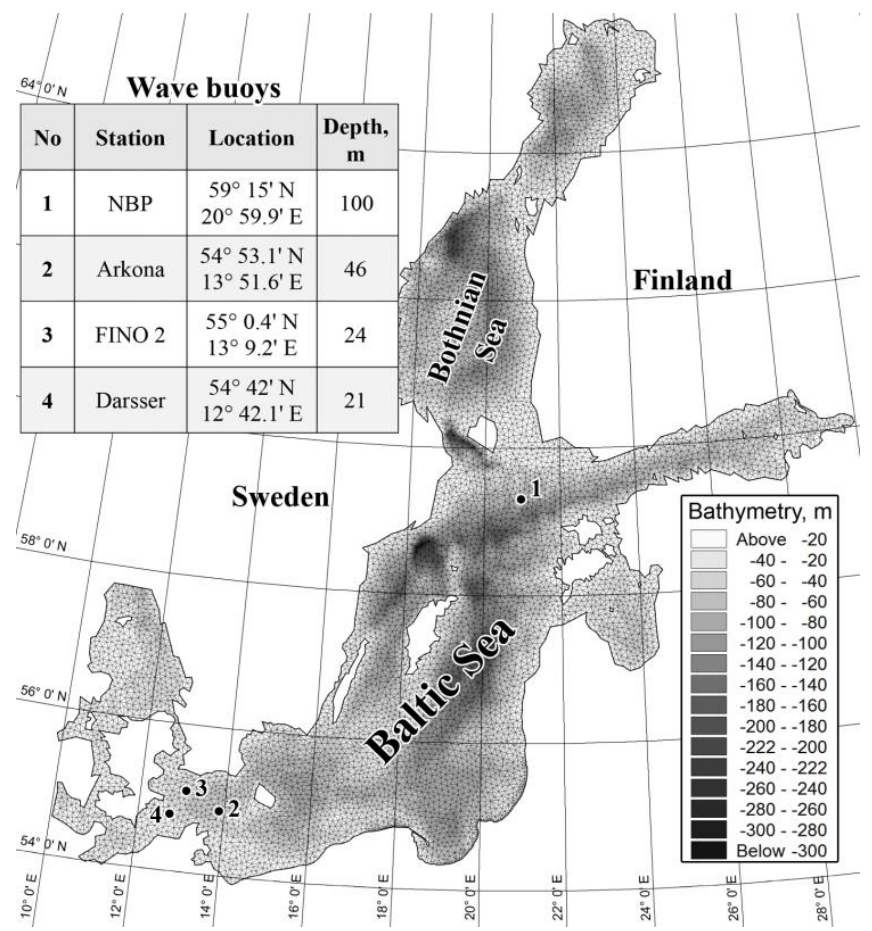

F i g. 1. Bathymetric map of the Baltic Sea and computational grid. Positions of the wave buoys (Directional Waverider) used for calibration are noted, their characteristics are cited 
The calculation is carried out by the finite element method on an irregular grid. The computational domain is shown in Fig. 1. Typical length of a grid element side is $6-10 \mathrm{~km}$, and the minimum one (in the coastal areas of the Southeastern Baltic) is $2-3 \mathrm{~km}$. The element size selection has two objectives. On the one hand, the element is obtained smaller than that of typical reanalysis systems, and, therefore, the spatial resolution is higher (especially for coastal waters). On the other hand, a sufficiently large side length of a grid element permits to increase the time step to a value, which no problems with the stability of the computational process arise at, and to reduce the computation time.

As shown by preliminary calculations, the parameters of the spectral discretization of the model significantly affect the computation time. For directional sampling, it is optimal to divide the circle into 24 sectors of 15 degrees. Frequency sampling covered the range from $0.05 \mathrm{~Hz}$ (wave period of $20 \mathrm{~s}$, typical only for very long swell waves, which are extremely rare in the Baltic Sea) to $0.5 \mathrm{~Hz}$ (wave period of $2 \mathrm{~s}$, typical for incipient wind waves).

\section{Boundary conditions}

The entire computational domain shown in Fig. 1, was considered a closed reservoir, i.e. the model had no open boundaries.

Since the present study was aimed to analyze the parameters of wind waves in the climatic period of time, it was necessary to find the same type of wind data for the Baltic Sea for a sufficiently long time interval. In this capacity, the ERAInterim global reanalysis data of the European Center for Medium-Range Forecasts, which are freely available, were selected ${ }^{2}$. The values of the wind speed components at an altitude of $10 \mathrm{~m}$ above sea level and the current ice situation data were extracted from the reanalysis data array. The calculation of the waves was carried out in case when the ice-free sea surface area in the current section was more than $66 \%$ (recommended value for MIKE $21 \mathrm{SW}$ ). The latitude and longitude resolution of the extracted data was 1 degree. The ERA-Interim time step is 6 hours.

\section{Calibration and validation}

The DHI MIKE $21 \mathrm{SW}$ model was widely used by the authors in previous studies $[10,11]$. The main calibration parameter of the model is $C_{\text {dis }}$ (the wave energy dissipation coefficient as a result of the whitecapping). Its value may depend both on the wind speed and direction, the location and, possibly, the characteristics of the wave buoy, the measurement data of which is used for calibration. In the present work, the calibration was carried out using data from wave buoys for July 2015 (Fig. 1). Fig. 2 shows the dependence of the significant wave height on time according to the wave buoy 1 measurements (NBP station) and the calculation results for the parameter values equal to 1, 3, and 5. Fig. 3 gives the same dependences for wave buoy 2 (Arkona station). It can be seen that equal $C_{\text {dis }}$ to 1 gives slightly overestimated results, and $C_{\text {dis }}$ equal to 5 - slightly underestimated ones.

\footnotetext{
2 ECMWF.

ERA-Interim.

2020.

[online]

Available

https://www.ecmwf.int/en/forecasts/datasets/reanalysis-datasets/era-interim [Accessed: 05 June 2020].
}

PHYSICAL OCEANOGRAPHY VOL. 27 ISS. 4 (2020) 


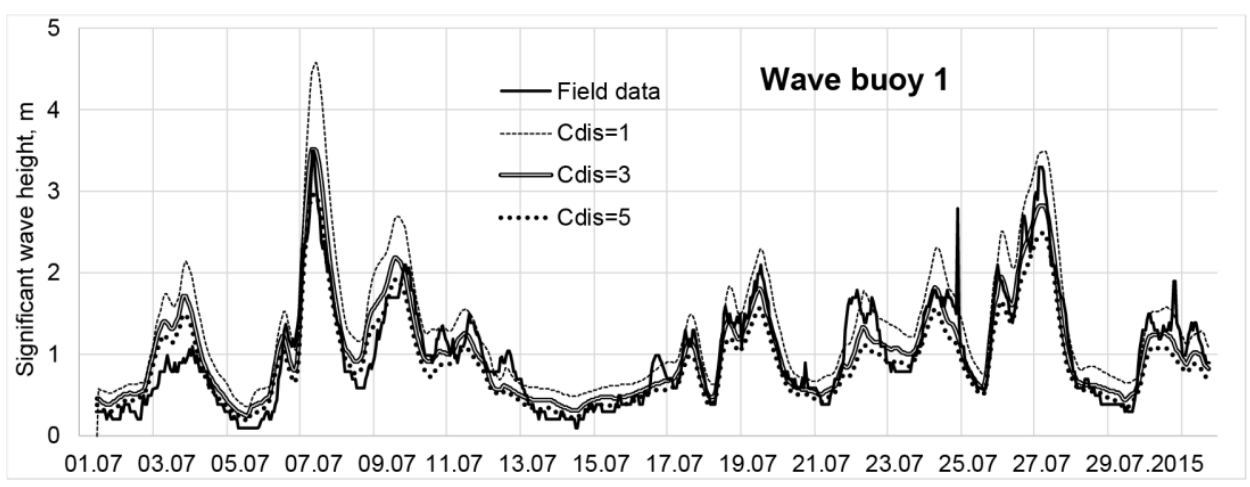

F i g. 2. Dependencies of a significant wave height upon time (1-31 July, 2015) at the location of buoy 1 (st. NBP) based on the field data and simulation results

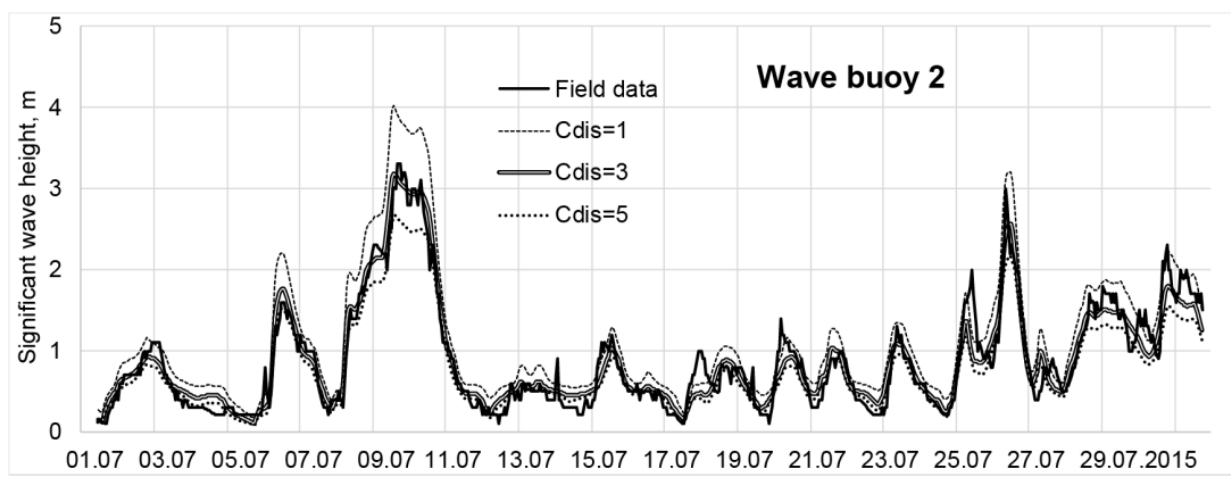

F i g. 3. Dependencies of a significant wave height upon time (1-31 July, 2015) at the location of buoy 2 (st. Arkona) based on the field data and simulation results

For more accurate assessment the optimal choice of the calibration parameter $C_{\mathrm{dis}}$, the comparison of the calculated and natural significant wave heights was carried out using the following statistical characteristics (Table 1):

- BIAS, $\mathrm{m}$ (the difference between the average significant wave height over the entire observation period and a similar calculated value),

- RMSE, m (root mean square error),

- $R$, dimensionless quantity (the Pearson correlation coefficient).

The model was validated based on data for January 2015 (Table 2). According to its results, for further calculations, it was decided to use the calibration parameter value $C_{\mathrm{dis}}$ equal to 3 as it gives the most reliable values of the wave parameters. 
Values of statistical parameters of waves for buoys 1, 2 and 4 (July, 2015)

\begin{tabular}{c|cccc|ccc|c|c|c|}
\hline \multirow{2}{*}{$C_{\text {dis }}$} & \multicolumn{3}{|c|}{ Buoy 1 } & \multicolumn{3}{c|}{ Buoy 2 } & \multicolumn{3}{c}{ Buoy 4 } \\
\cline { 2 - 11 } & BIAS, m & $R M S E, \mathrm{~m}$ & $R$ & BIAS, $\mathrm{m}$ & $R M S E, \mathrm{~m}$ & $R$ & $B I A S, \mathrm{~m}$ & $R M S E, \mathrm{~m}$ & $R$ \\
\hline 1.0 & -0.31 & 0.349 & 0.92 & -0.25 & 0.440 & 0.96 & -0.21 & 0.287 & 0.94 \\
1.5 & -0.21 & 0.273 & 0.92 & -0.17 & 0.354 & 0.96 & -0.15 & 0.237 & 0.94 \\
2.0 & -0.13 & 0.225 & 0.92 & -0.11 & 0.304 & 0.96 & -0.10 & 0.206 & 0.94 \\
2.5 & -0.07 & 0.198 & 0.92 & -0.06 & 0.276 & 0.96 & -0.06 & 0.188 & 0.94 \\
3.0 & $-\mathbf{0 . 0 2}$ & $\mathbf{0 . 1 8 7}$ & 0.92 & $\mathbf{- 0 . 0 2}$ & $\mathbf{0 . 2 6 5}$ & 0.96 & -0.03 & $\mathbf{0 . 1 8 1}$ & 0.94 \\
3.5 & $\mathbf{0 . 0 2}$ & 0.188 & 0.92 & $\mathbf{0 . 0 2}$ & $\mathbf{0 . 2 6 4}$ & 0.96 & $\mathbf{0 . 0 0}$ & $\mathbf{0 . 1 8 1}$ & 0.94 \\
4.0 & 0.06 & 0.198 & 0.92 & 0.05 & 0.270 & 0.96 & 0.03 & 0.186 & 0.94 \\
4.5 & 0.09 & 0.214 & 0.92 & 0.08 & 0.281 & 0.96 & 0.05 & 0.195 & 0.94 \\
5.0 & 0.12 & 0.233 & 0.92 & 0.11 & 0.295 & 0.96 & 0.08 & 0.207 & 0.94 \\
\hline
\end{tabular}

$\mathrm{N}$ o t e : the best values are in bold.

Table 2

Values of statistical parameters of waves for buoys 1, 2 and 3 (January, 2015)

\begin{tabular}{c|ccc|c|c|c|c|c|c|c}
\hline & \multicolumn{3}{|c|}{ Buoy 1 } & \multicolumn{3}{c|}{ Buoy 2 } & \multicolumn{3}{c}{ Buoy 3 } \\
\hline$C_{\text {dis }}$ & BIAS, m & $R M S E, \mathrm{~m}$ & $R$ & BIAS, m & $R M S E, \mathrm{~m}$ & $R$ & BIAS, $\mathrm{m}$ & $R M S E, \mathrm{~m}$ & $R$ \\
\hline 1.0 & -0.44 & 0.666 & 0.95 & -0.38 & 0.655 & 0.94 & -0.36 & 0.606 & 0.94 \\
1.5 & -0.23 & 0.491 & 0.95 & -0.24 & 0.518 & 0.94 & -0.23 & 0.469 & 0.94 \\
2.0 & -0.07 & 0.394 & 0.95 & -0.14 & 0.430 & 0.94 & -0.14 & 0.379 & 0.94 \\
2.5 & $\mathbf{0 . 0 5}$ & $\mathbf{0 . 3 6 0}$ & 0.95 & -0.05 & 0.374 & 0.94 & -0.06 & 0.32 & 0.94 \\
3.0 & 0.16 & 0.374 & 0.95 & $\mathbf{0 . 0 2}$ & 0.343 & 0.94 & $\mathbf{0 . 0 1}$ & 0.286 & 0.94 \\
3.5 & 0.25 & 0.414 & 0.95 & 0.08 & $\mathbf{0 . 3 3 1}$ & 0.94 & 0.06 & $\mathbf{0 . 2 7 2}$ & 0.94 \\
4.0 & 0.33 & 0.465 & 0.95 & 0.13 & 0.336 & 0.94 & 0.12 & 0.275 & 0.94 \\
4.5 & 0.40 & 0.521 & 0.95 & 0.19 & 0.352 & 0.94 & 0.16 & 0.291 & 0.94 \\
5.0 & 0.46 & 0.576 & 0.95 & 0.23 & 0.376 & 0.94 & 0.21 & 0.314 & 0.94 \\
\hline
\end{tabular}

$\mathrm{N}$ o t e : the best values are in bold.

\section{Results and discussion}

The calibrated model was used to calculate the parameters of wind waves for the entire Baltic Sea for 1979-2018 with 1-hour interval, which served as the initial data for assessing their temporal variability over 40 years. For the further processing convenience, the spatio-temporal distributions of wave parameters obtained on an irregular grid were brought to a regular grid with a cell size of approximately $21 \times 21 \mathrm{~km}$. The resulting regular grid had 60 cells in the longitudinal direction and 65 - in the latitudinal direction.

The distribution of the significant wave heights maxima obtained as a result of statistical processing for the considered period 1979-2018 (40 years old) is shown in the inset (Fig. 4,a). This representation is not one-time, but integral - each cell in this figure reflects the maximum significant wave height recorded at a certain moment over 40 years in this cell. The maximum waves are shown to be confined to the water area around Gotland Island in the Central Baltic, Bornholm Island and the Gdansk basin center. 


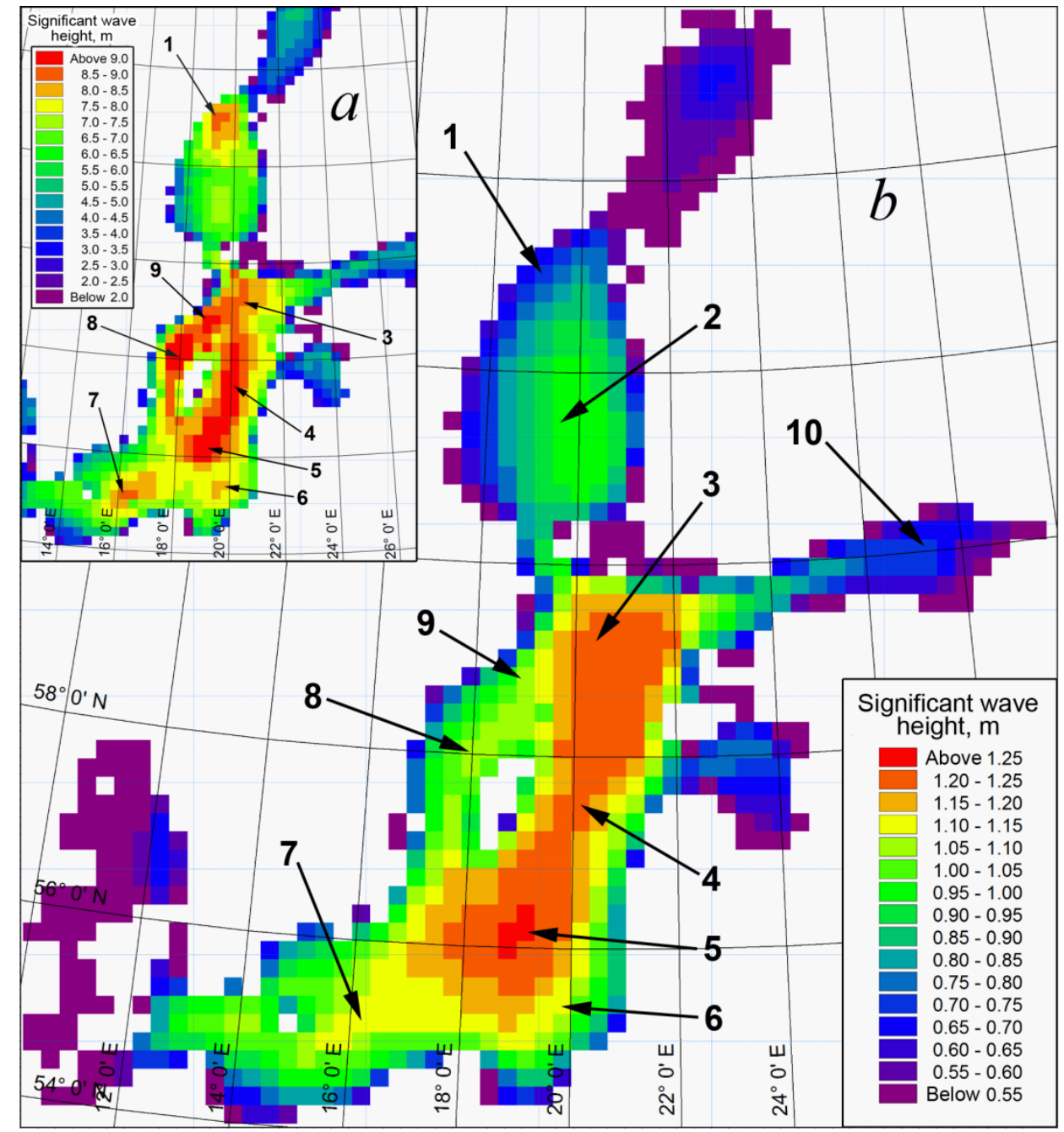

F i g. 4. Significant wave heights: $a$-maximum values recorded over 40 years; $b-40$-year averaged values $(1-10-$ control cells)

40 year-averaged significant wave heights obtained as a result of calculations, are shown in Fig. 4, $b$. It can be seen that the maximum values of this parameter are observed in the Central Baltic at a considerable distance from the coast. The region of maximum values is shifted from the longitudinal axis of the sea by about $50-100 \mathrm{~km}$ towards the eastern coast and corresponds to the largest fetches for the dominant westerly and southwestern winds.

\section{Time series analysis}

The control cells which the time series were extracted from for the significant wave heights averaged over the calendar year to analyze the trends in the wind wave heights variability are numbered in Fig. $4, b$ (from 1 to 10). Most of the selected control cells correspond to those regions in which the maximum 
significant wave height over 40 years under study were recorded. Control cells 1 and 3-9 were selected as there were cases where the calculated values of significant wave heights exceeded $8 \mathrm{~m}$. In control cells 2 and 10, the calculations did not show such high waves, nevertheless, these cells were added to the study for the better coverage of the Baltic Sea.

The area represented by control cell 5 is characterized by the maximum average significant wave height in it over the entire Baltic Sea for the entire considered period (Fig. 4). Linear regression calculation [12, 13] using the least squares method (linear regression coefficients and their errors at a $90 \%$ confidence level) shows a negative trend to be revealed in this control cell: a decrease in the average annual significant wave height is $(2.3 \pm 7.5) \cdot 10^{-3} \mathrm{~m} / \mathrm{year}$, and the true regression line is (with $90 \%$ probability) within the confidence limits bounded by dashed lines in Fig. 5.

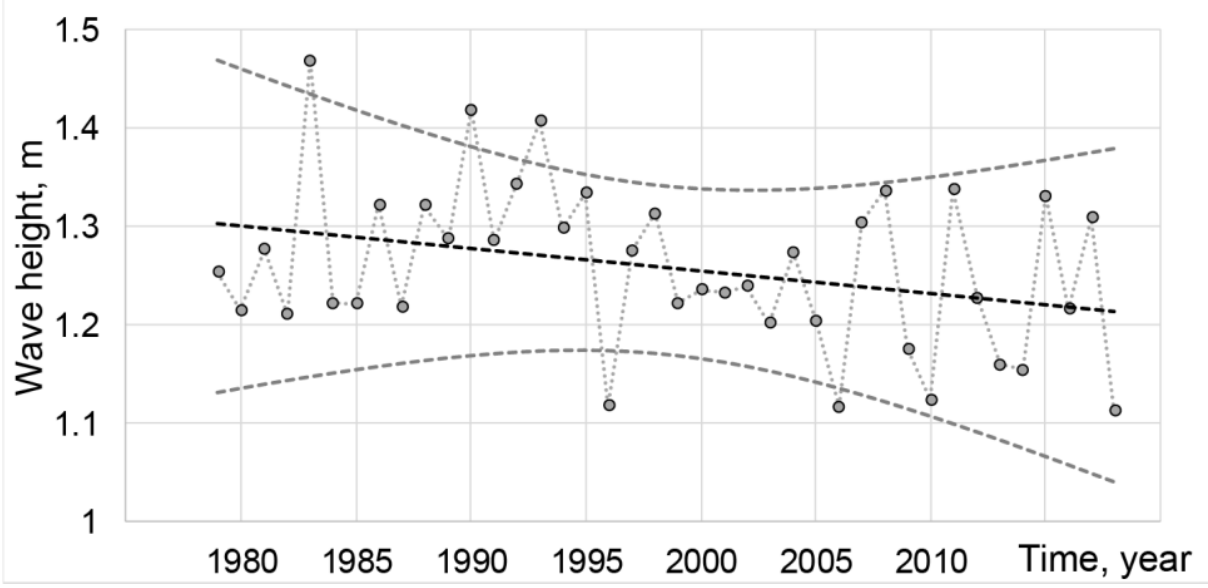

F i g. 5. Time series for annual average significant wave height in cell 5 (see Fig. 4), trend line (bold dotted line) and its 90\%-confidence limits (thin dotted line)

Time series analysis for all other control cells (Fig. 6) shows that negative trends are also observed for these cells: the average annual significant wave heights over the past 40 years have been decreasing at a speed that is maximum in the Southeastern Baltic (control cells 5 and 6, see Fig. 4) and the minimum in the Gulfs of Bothnia and Finland (control cells 1, 2 and 10, see Fig. 4). Speaking about the statistical significance of the identified trends, it should be noted that in all the cases considered, the error in estimating their coefficients at $90 \%$ confidence level exceeds the values found. Thus, no statistically significant trends were revealed in the studied time interval, although a tendency towards a decrease in the intensity of the waves is traced. 

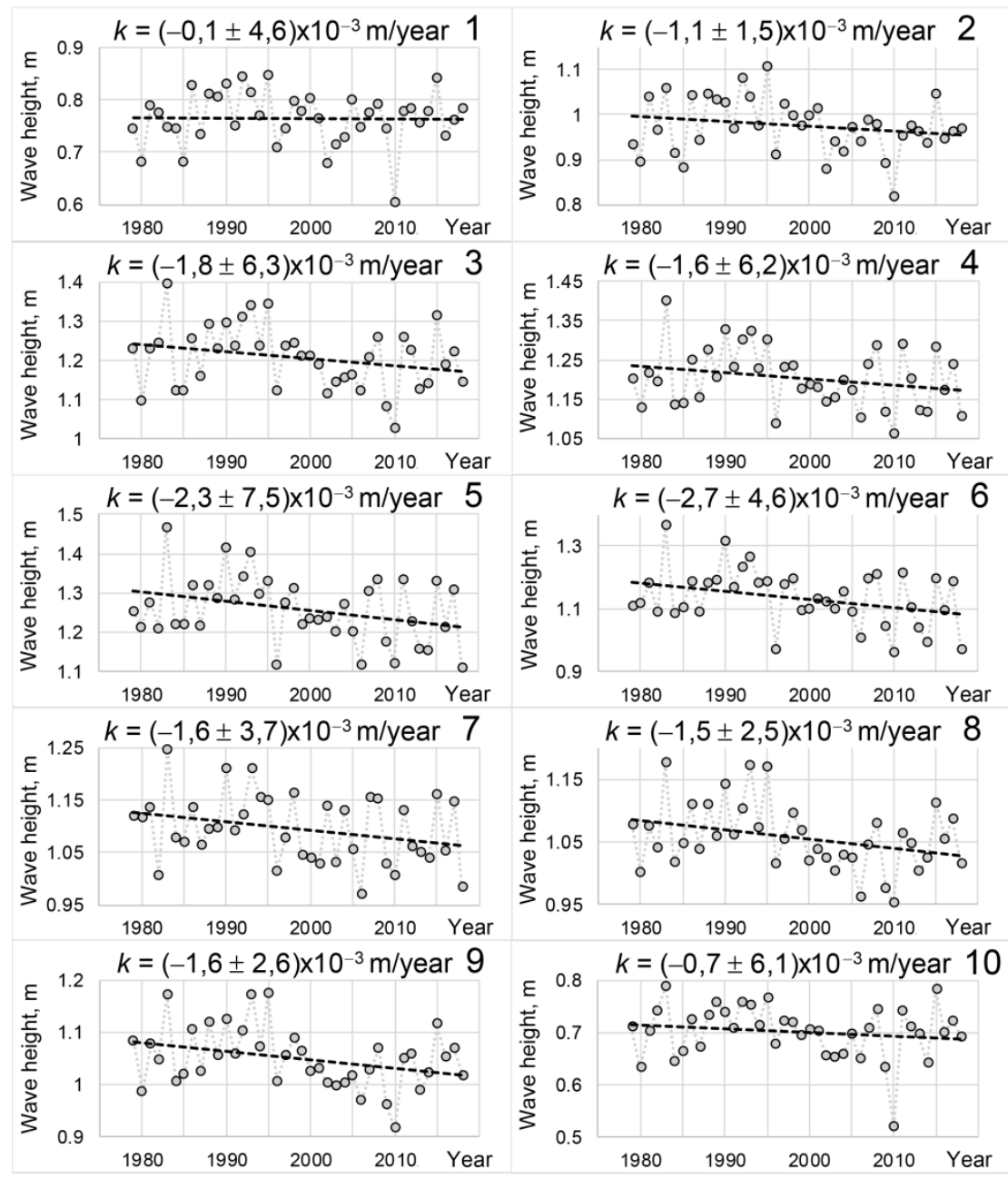

F i g. 6. Time series of annual average significant wave height in control cells 1-10 (see Fig. 4) and their linear trends. Confidence level is $90 \%$

It is of interest to compare the interannual variability of the annual average significant wave height with its changes along the entire period trend (i.e., with the difference between the extreme values of the trend line). The results of this comparison are shown in Table 3. For example, for cell 5, the decrease in the average annual significant wave height in accordance with the revealed trend is $\sim 0.09 \mathrm{~m}$ over 40 years. At the same time, the average interannual variability of this parameter, observed over 40 years, is characterized by an average value of $0.1 \mathrm{~m}$, and a maximum of $0.26 \mathrm{~m}$. It can be seen that the average values of interannual variability and trend changes over 40 years have the same order of magnitude in all control cells, except for the $1^{\text {st }}$ (northern part of the Bothnian Sea), where the trend is the weakest. The fact that the interannual variability of the annual average significant wave height and changes along the trend for the entire period are numbers of the same order of magnitude, testifies to the conclusion that the trend exists. 
Interannual variability of the annual average significant wave height and its trend change (absolute values)

\begin{tabular}{c|cc|c}
\hline \multirow{2}{*}{ Cell } & \multicolumn{2}{|c|}{ Interannual variability, $10^{-2} \mathrm{~m}$} & Trend change for 40 years, \\
\cline { 2 - 3 } & Average & Maximum & 0.4 \\
\hline 1 & 6 & 17 & 4.4 \\
2 & 7 & 20 & 7.2 \\
3 & 8 & 27 & 6.4 \\
4 & 9 & 27 & 9.2 \\
5 & 10 & 26 & 11.0 \\
6 & 10 & 28 & 6.4 \\
7 & 8 & 24 & 6.0 \\
8 & 6 & 16 & 6.4 \\
9 & 6 & 17 & 2.8 \\
10 & 5 & 22 & 6,0
\end{tabular}

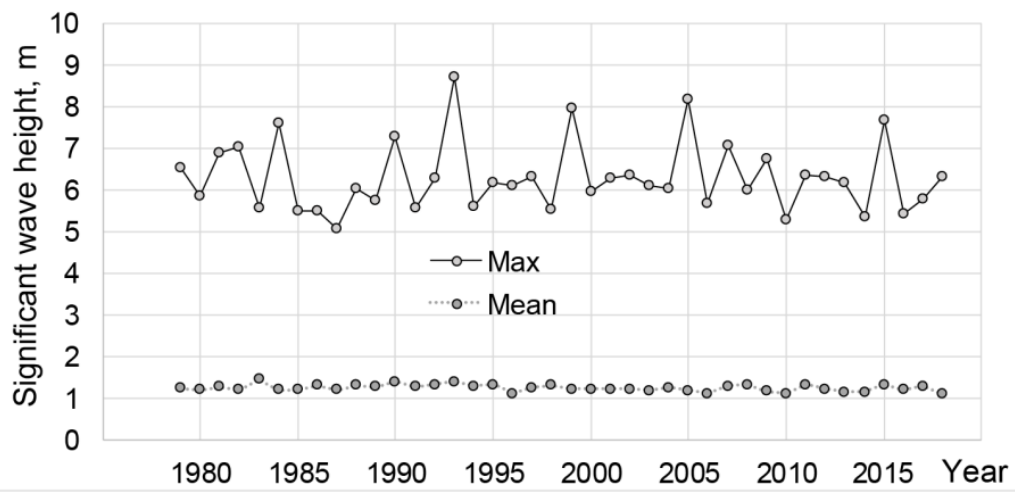

F i g. 7. Maximum and average annual values of significant wave heights for cell 5 (see Fig. 4)

As for the maximum annual significant wave heights, there is no need to talk about any trends: the spread is very large from year to year. A typical time series (for control cell 5, see Fig. 4) is shown in Fig. 7. For comparison, a time series of the average significant wave heights is also presented. Calculation of the linear trend of the maximum values gives $(-1.5 \pm 128.0) \cdot 10^{-3} \mathrm{~m} / \mathrm{year}$. Although for average values of significant wave heights the trend coefficient error exceeds the trend coefficient value $\left((-2.3 \pm 7.5) \cdot 10^{-3} \mathrm{~m} /\right.$ year $)$, it coincides with it in order of magnitude, then for the maximum values the trend coefficient error is two orders of magnitude greater than the coefficient itself.

Tendency for the waves weakening for the entire Baltic Sea is confirmed by comparing the significant height and power of the waves for the first and last decades of the 40-year period under consideration. The comparison was carried out as follows: the fields of the average significant wave height and wave power for 1979-1988 and 2009-2018 were calculated. Their difference (values for the last decade minus values for the first decade) is shown in Fig. 8. Increase (extremely insignificant) in height and power of waves is observed only in the northern parts 
of the Bothnian Sea and the Gulf of Bothnia. In the rest of the water area, a decrease in the average annual values of these parameters is monitored. It is the most noticeable in the Southeastern Baltic.

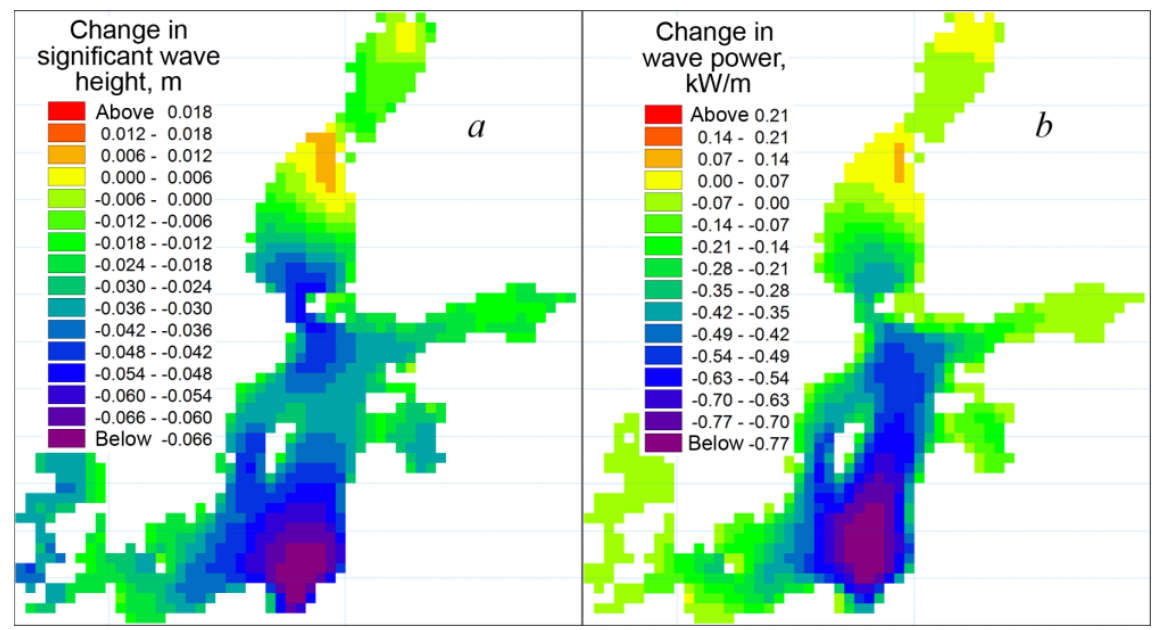

F i g. 8. Differences between the significant wave height $(a)$ and wave power $(b)$ average values in the last (2009-2018) and the first (1979-1988) decades of the time interval under study

\section{Conclusions}

The average annual significant wave heights in almost the entire Baltic Sea area over the past 40 years have a tendency to decrease with the rate not exceeding 2-3 mm per year or $\sim 0.2-0.3 \%$ per year. The highest decrease rate is observed in the Southeastern Baltic, the lowest - in the Bothnian Sea, Gulf of Bothnia and Gulf of Finland. The interannual variability of the annual average significant wave height and its trend changes over the entire 40-year period are of the same order of magnitude.

\section{REFERENCES}

1. Broman, B., Hammarklint, T., Rannat, K., Soomere, T. and Valdmann, A., 2006. Trends and Extremes of Wave Fields in the North-Eastern Part of the Baltic Proper. Oceanologia, 48(S), pp. 165-184. Available at: https://www.etis.ee/File/DownloadPublic/942d20a6-1b5940f6-a000-45bd8a3c504c?name=

Fail_Oceanologia_2006_Broman_etal.pdf\&type=application\%2Fpdf [Accessed: 03 July 2020].

2. Cieślikiewicz, W. and Paplińska-Swerpel, B., 2008. A 44-year Hindcast of Wind Wave Fields over the Baltic Sea. Coastal Engineering, 55(11), pp. 894-905. https://doi.org/10.1016/j.coastaleng.2008.02.017

3. Medvedeva, A.Yu., Arkhipkin, V.S., Myslenkov, S.A. and Zilitinkevich, S.S., 2015. Wave Climate of the Baltic Sea Following the Results of the Swan Spectral Model Application. Vestnik Moskovskogo Universiteta. Seriya 5, Geografiya, (1), pp. 12-22 (in Russian).

4. Björkqvist, J.-V., Lukas, I., Alari, V., van Vledder, G.Ph., Hulst, E., Pettersson, H., Behrens, A. and Männik, A., 2018. Comparing a 41-year Model Hindcast with Decades of Wave Measurements from the Baltic Sea. Ocean Engineering, 152, pp. 57-71. https://doi.org/10.1016/j.oceaneng.2018.01.048 
5. Soomere, T. and Räämet, A., 2011. Spatial Patterns of the Wave Climate in the Baltic Proper and the Gulf of Finland. Oceanologia, 53(1-TI), pp. 335-371. Available at: https://www.iopan.pl/oceanologia/531Tsoom.pdf [Accessed: 03 July 2020].

6. Soomere, T. and Räämet, A., 2011. Long-Term Spatial Variations in the Baltic Sea Wave Fields. Ocean Science, 7(1), pp. 141-150. doi:10.5194/os-7-141-2011

7. Drabkin, V.V., Fokina, M.L., Klyachkin, S.V. and Gasnikova, N.V., 1992. [Ice Regime of the Baltic Sea]. In: F. S. Terziyeva, V. A. Rozhkova, A. I. Smirnovoy, eds., 1992. [Hydrometeorology and Hydrochemistry of the USSR Seas. Vol. 3. Baltic Sea. Issue 1. Hydrometeorological Conditions]. Saint Petersburg: Gidrometeoizdat. Chapter 4.6, pp. 320329 (in Russian).

8. Divinsky, B.V. and Kosyan, R.D., 2017. Spatiotemporal Variability of the Black Sea Wave Climate in the Last 37 years. Continental Shelf Research, 136, pp.1-19. https://doi.org/10.1016/j.csr.2017.01.008

9. DHI, 2007. MIKE 21 Wave Modelling. MIKE 21 Spectral Waves FM: Short description. Horsholm: DHI, 14 p. Available at: https://www.mikepoweredbydhi.com/$/$ media/shared $\% 20$ content/mike $\% 20$ by $\% 20 \mathrm{dhi} /$ flyers $\% 20$ and $\% 20 \mathrm{pdf} /$ product documentation/short\%20descriptions/mike21_sw_fm_short_description.pdf [Accessed: 03 July 2020].

10. Sokolov, A.N. and Chubarenko, B.V., 2014. Sensitivity Analysis for Wave Regime in Wave-Deformation Zone in the South-Eastern Baltic in a View of Possible Climate Changes. KSTU News, (34), pp. 43-51. Available at: http://klgtu.ru/upload/science/magazine/news_kstu/2014_34/sokolov.pdf [Accessed: 06 July 2020] (in Russian).

11. Sokolov, A. and Chubarenko, B., 2018. Numerical Simulation of Dynamics of Sediments Disposed in the Marine Coastal Zone of the South-Eastern Baltic. Baltica, 31(1), pp. 13-23. https://doi.org/10.5200/baltica.2018.31.02

12. Draper, N.R. and Smith, H., 1981. Applied Regression Analysis. 2-nd ed. New York: John Wiley and Sons, 709 p.

13. Pakhteev, A. and Stepanov, A., 2019. On Simulation of Normal Records. Communications in Statistics - Simulation and Computation, 48(8), pp. 2413-2424. doi:10.1080/03610918.2018.1457692

About the authors:

Andrei N. Sokolov - Senior Research Associate, P.P. Shirshov Istitite of Oceanology RAS (36 Nahimovskiy prospect, Moscow, 117997, Russian Federation); Assistant Professor, Immanuel Kant Baltic Federal University (4A Nevskogo St., Kaliningrad, 236041, Russian Federation), Ph. D. (Tech. Sci.), ResearcherID: B-4523-2017, Scopus Author ID: 56998131000, ORCID ID: 0000-0002-7593-9739, tengritag@gmail.com

Boris V. Chubarenko - Head of the laboratory, P.P. Shirshov Istitite of Oceanology RAS (36 Nahimovskiy prospect, Moscow, 117997, Russian Federation), Ph. D. (Phys.-Math.), Leading Research Associate, ResearcherID: I-6118-2016, Scopus Author ID: 6507102508, ORCID ID: 0000-0001-7988-1717, chuboris@mail.ru

Contribution of the co-authors:

Andrei N. Sokolov - preparation of the mathematical model and carrying out the calculations, data visualization and presentation, its analysis and preparation of the initial version of the article text

Boris V. Chubarenko - scientific supervision, qualitative analysis of the results and their interpretation, critical analysis and revision of the article text

All the authors have read and approved the final manuscript.

The authors declare that they have no conflict of interest. 